\title{
Trends in indices of daily precipitation extremes in Catalonia (NE Spain), 1951-2003
}

\author{
M. Turco and M. C. Llasat \\ Department of Astronomy and Meteorology, University of Barcelona, Barcelona, Spain \\ Received: 2 June 2011 - Revised: 13 September 2011 - Accepted: 28 September 2011 - Published: 9 December 2011
}

\begin{abstract}
The aim of this paper is to quantitatively characterize the climatology of daily precipitation indices in Catalonia (northeastern Iberian Peninsula) from 1951 to 2003. This work has been performed analyzing a subset of the ETCCDI (Expert Team on Climate Change Detection and Indices) precipitation indices calculated from a new interpolated dataset of daily precipitation, namely SPAIN02, regular at $0.2^{\circ}$ horizontal resolution (around $20 \mathrm{~km}$ ) and from two high-quality stations: the Ebro and Fabra observatories.

Using a jack-knife technique, we have found that the sampling error of the SPAIN02 regional averaged is relatively low. The trend analysis has been implemented using a Circular Block Bootstrap procedure applicable to nonnormal distributions and autocorrelated series. A running trend analysis has been applied to analyze the trend persistence. No general trends at a regional scale are observed, considering the annual or the seasonal regional averaged series of all the indices for all the time windows considered. Only the consecutive dry days index (CDD) at annual scale shows a locally coherent spatial trend pattern; around $30 \%$ of the Catalonia area has experienced an increase of around 2-3 days decade ${ }^{-1}$. The Ebro and Fabra observatories show a similar CDD trend, mainly due to the summer contribution. Besides this, a significant decrease in total precipitation (around $-10 \mathrm{~mm} \mathrm{decade}^{-1}$ ) and in the index "highest precipitation amount in five-day period" (RX5DAY, around $-5 \mathrm{~mm} \mathrm{decade}^{-1}$ ), have been found in summer for the Ebro observatory.
\end{abstract}

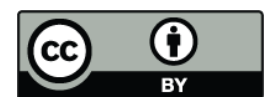

Correspondence to: M. Turco (mturco@am.ub.es)

\section{Introduction}

The objective of this study is to analyse day-count precipitation indices in Catalonia (northeastern Iberian Peninsula) during the second half of the 20th Century in order to better understand the past variability of climate extremes with short return periods and set up a base to develop climate regional scenarios.

The motivation for this work derived mainly from the three following points. Firstly, the vulnerability of communities and ecosystems to climate variability depends more on the change of extreme events at a regional scale than on changes in mean climate over larger areas (Alexander et al., 2009). Particularly, precipitation plays a major role in water resources and in natural hazards in Catalonia (Llasat, 2009), leading to one of the most vulnerable regions to water scarcity, droughts and floods in Europe (Kristensen, 2010; Llasat et al., 2005; Barrera et al., 2006). Secondly, it is important to study the Mediterranean climate because it has been identified as one of the most prominent "Hot-Spots" in future climate change projections (Giorgi, 2006). In effect, the Mediterranean region lies in a transition area between extratropical and subtropical influence, so slight modifications of the general circulation might cause changes in the climate (Giorgi and Lionello, 2008).

Thirdly, the present state-of-the-art for trend analysis offers results that on some occasions do not agree with each other. A rather controversial picture appears in the studies on the precipitation trend, not only considering the Northeast of Spain but also the Mediterranean area in general. Absent or non-significant precipitation trends are found at the Mediterranean scale (Norrant and Douguedroit, 2005), although some isolated regions show an increase in extreme rainfall in spite of a decrease in totals (Alpert et al., 2002) or changes in the seasonal pattern of the rainfall

Published by Copernicus Publications on behalf of the European Geosciences Union. 


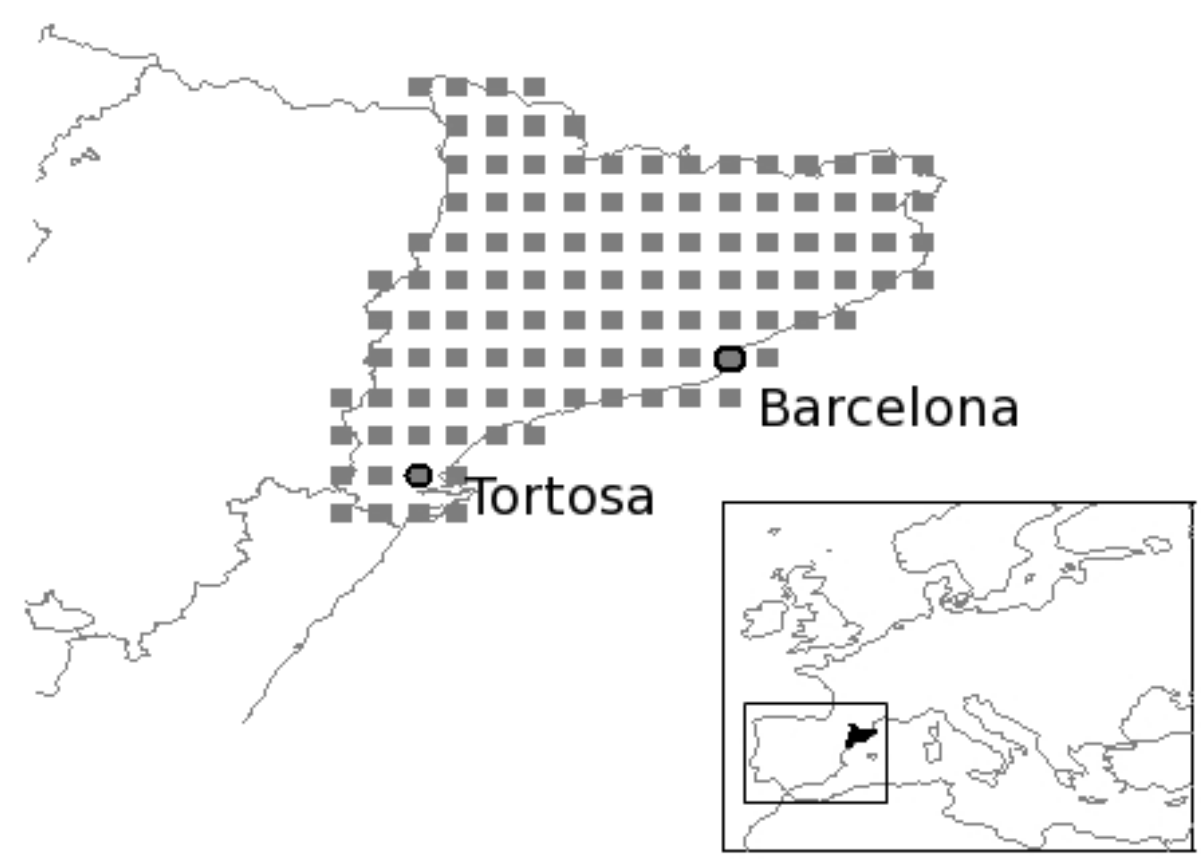

Fig. 1. Region of study and position of the SPAIN02 grid-points and the two observatories (Ebro, close to Tortosa and Fabra, close to Barcelona).

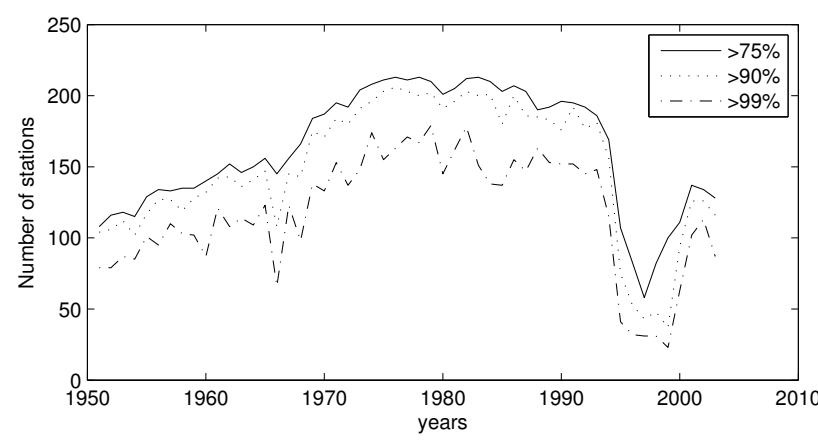

Fig. 2. Temporal variability of the number of available stations in Catalonia with at least $75 \%, 90 \%$, and $99 \%$ of valid daily data for every year.

regime (e.g. Pujol et al., 2007). The Mediterranean coast of the Iberian Peninsula does not present any clear significant trend, at least at annual scale (Llasat and Quintas, 2004; Gonzalez-Hidalgo et al., 2009; Altava-Ortiz et al., 2010; Río et al., 2011), although some trends are found with high sensitivity to the study period and with high variability within and between regions (Goodess and Jones, 2002; López-Moreno et al., 2010). If the analysis of the average values may have disagreements, the problem is exacerbated considering the daily indices. For example, several studies coincide in stating that much of the Iberian Peninsula has experienced a decrease in the intensity of precipitation daily, while the number of days with light rain have increased (García et al., 2007; Rodrigo and Trigo, 2007; Rodrigo, 2010).
Instead, Serra et al. (2006); López-Moreno et al. (2010) indicate that also the number of rainy days has decreased.

These differences could be explained by the intrinsic difficulties in the analysis of series with high interannual variability and relatively low trends (as probably happens in this case) and/or when the trends show high variability in space. Moreover, other factors can influence the trend analysis: the dataset (e.g. number of stations and period investigated), the definition of the rainfall indices, and also the methodology applied to estimate the trend (Pryor et al., 2009).

Taking all these considerations into account, in this study we set out to perform a robust statistical analysis of the precipitation extreme indices using Monte-Carlo techniques (e.g. bootstrap and jack-knife methods) to estimate sampling error and to assess the significance of the results. In order to analyse the data in a comparable way, we consider a subset of the "moderate extreme" precipitation indices defined by the World Meteorological Organization (WMO) CC1/CLIVAR/JCOMM Expert Team on Climate Change Detection and Indices (ETCCDI, for more details see http: //cccma.seos.uvic.ca/ETCCDI or WMO, 2009). The ETCCDI indices are calculated from a new, recently developed dataset of daily precipitation for a grid of $20 \mathrm{~km}$, namely SPAIN02 (Herrera et al., 2010a), which is the reference dataset for the esTcena Spanish project and is being used to validate the climate model outputs in Spain (Herrera et al., 2010b; Turco et al., 2011). The ETCCDI indices are also calculated for the largest high-quality stations in Catalonia with daily precipitation data: Ebro and Fabra observatories. 
(a) Spain02
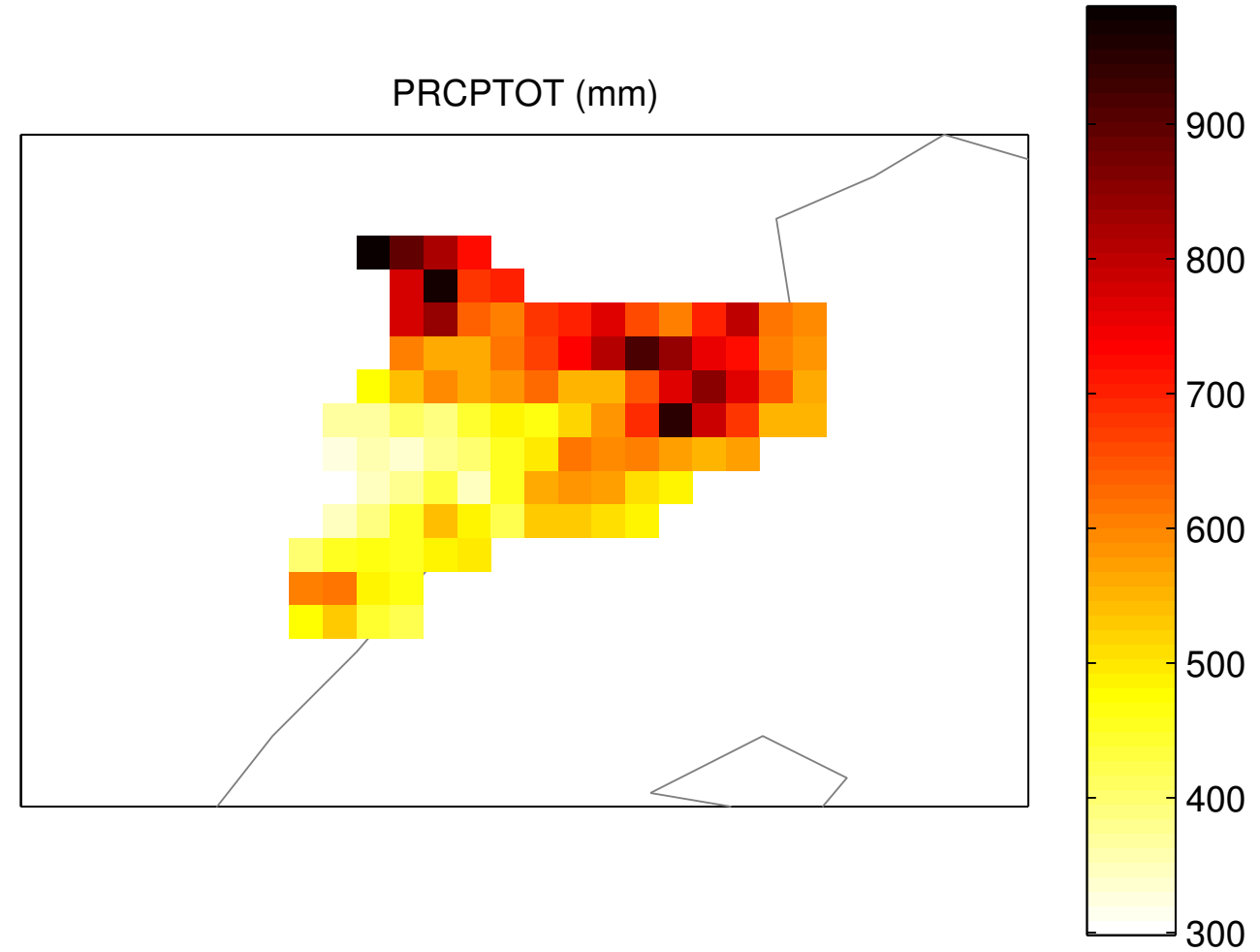

(b) SMC
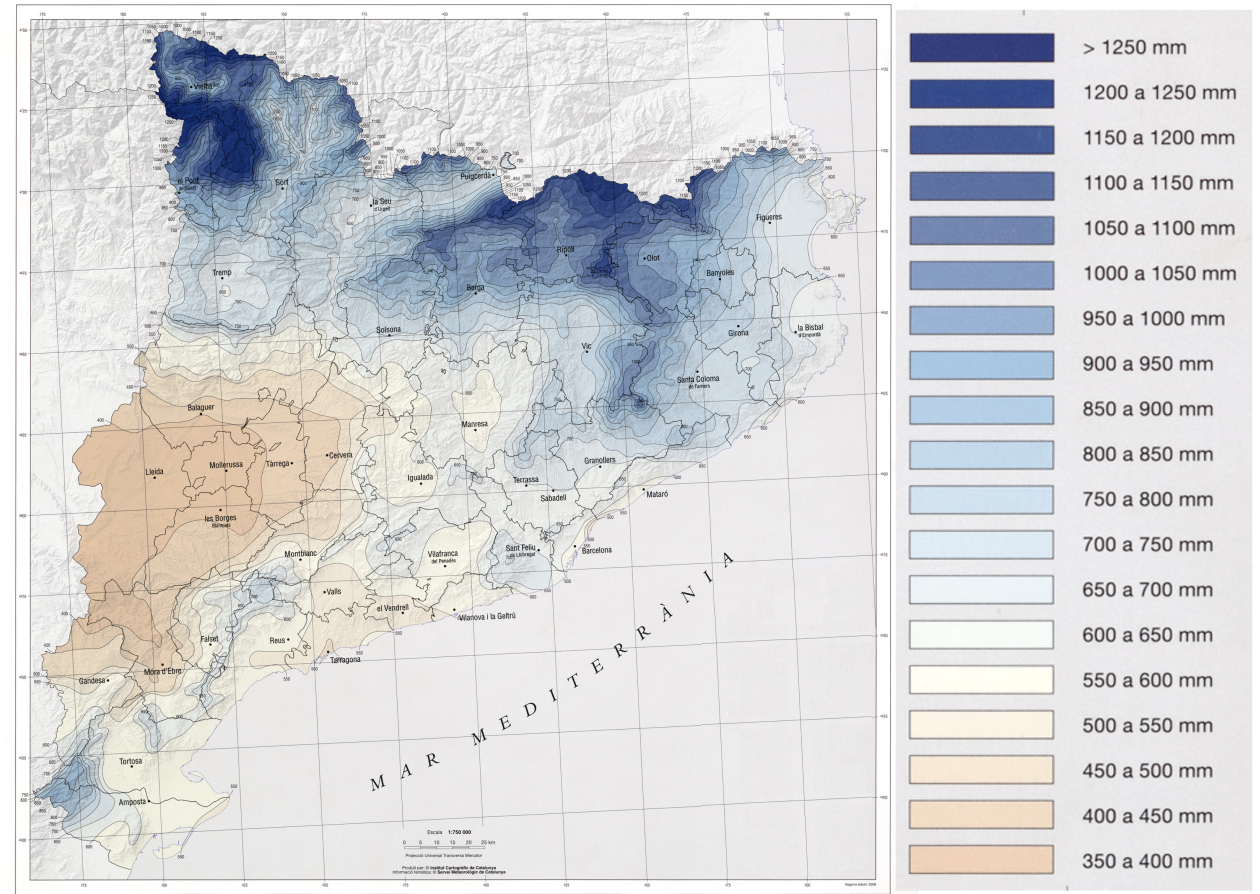

Fig. 3. Annual precipitation climatology of (a) the Spain02 grid and of (b) the climate atlas published by the Meteorological Service of Catalonia (SMC). 
The study is organized as follows. In Sect. 2, a description of the data used is given whereas their characteristics as well as their representativeness is discussed in Sect. 3. Section 4 is concerned with trend analysis. Finally, Sect. 5 synthesizes the main results and conclusions of this study.

\section{Data and indices}

\subsection{Interpolated observations: Spain02}

The time series of daily precipitation in Catalonia (Fig. 1) have been analyzed using the high-resolution (regular at $0.2^{\circ} \times 0.2^{\circ}$, approximately $20 \mathrm{~km} \times 20 \mathrm{~km}$ ) gridded dataset referred to as SPAIN02. This dataset has been obtained from 2756 (263 located in the study area) quality-controlled stations from the Spanish Meteorological Agency (AEMET), covering the Iberian Peninsula and Balearic Islands over the period from 1 January 1950 to 31 December 2003. Readers are referred to Herrera et al. (2010a) for the development and analysis of the SPAIN02 dataset. This paper is focused on the subset of 112 grid points within Catalonia.

Figure 2 shows the temporal evolution of the number of available stations used to build the dataset, for three different thresholds of valid daily data for every year. This temporal variability as well as the spatial sparseness of the stations used to build the dataset should be borne in mind by any user of the SPAIN02 dataset (Hofstra et al., 2009; Herrera et al., 2010a).

There was a large decrease in the number of available stations between 1995 and 2000. This fact is quite general in Spain (Herrera et al., 2010a) and the transition to automatic stations and the abandonment of manual stations could be two reasons for this decrease. In the next sections, the error associated with the spatial/temporal variability in the available stations (hereafter named sampling error) is addressed.

\subsection{Reference stations}

This study has been completed with the daily precipitation series of the Fabra Observatory (close to Barcelona), and Ebro Observatory (close to Tortosa; Fig. 1):

- Fabra Observatory: lat. 41.42 N, lon. 2.12 E and $411 \mathrm{~m}$ a.m.s.l.

- Ebro Observatory: lat. $40.82 \mathrm{~N}$, lon. $0.49 \mathrm{E}$ and $51 \mathrm{~m}$ a.m.s.l.

These two stations have been chosen as reference series since their continuity is assured (for both stations for the period considered, i.e. 1951-2003, there are no missing data), correct measurement practice is guaranteed, and, finally, there are no documented variations of the station instrumentation or in its environment. These series of precipitation are homogeneous with respect to the tests conducted by Wijngaard et al. (2003). These are the international reference stations also used for the report of the climatic change in Catalonia (Cunillera, 2009).

\subsection{ETCCDI indices}

Working with daily data (without missing values) allows calculation of a subset of the standard statistical indicators of extreme precipitation (ETCCDI indices, Table 1). These selected subsets of indices summarize the behaviour of the precipitation, describing some standard indices, such as the total precipitation (PRCPTOT) and the precipitation intensity (SDII), and also some moderate (with short return period) extreme indices related to critical consequence, such as the percentage of precipitation due to very wet days (R95pTOT/PRCPTOT, hereinafter named R95p). This index could indicate the possibility that there was a larger change in extreme precipitation events than in the total precipitation. The highest precipitation amount over a five-day period (RX5DAY) could be related to the major floods and the maximum length of dry spell (CDD) could be related to the most intense drought.

The values of these indices are calculated at annual and seasonal scale. In order to analyze the data in a standardized way (WMO, 2009) we consider the following definition:

- The "meteorological year": from 1 December to 30 November.

- The "meteorological season": winter (DJF), spring (MAM), summer (JJA) and autumn (SON).

- A "dry day" is defined as a day with less precipitation than $1 \mathrm{~mm}$ day $^{-1}$.

\section{Data characteristics and representativeness}

\subsection{Spatial distribution of daily precipitation indices}

Figures 3 and 4 show the climatology of the indices studied. A visual comparison between the total precipitation climatology obtained using SPAIN02 and the one published in the Climatological Atlas of Catalonia (Ninyerola et al., 2003) has been done (Fig. 3). Both maps show good agreement. In effect, Herrera et al. (2010a) demonstrates that the SPAIN02 dataset captures the great precipitation variability all over Spain.

Despite the relatively small size of the selected region (around $32000 \mathrm{~km}^{2}$ ), the spatial distributions of daily precipitation indices vary widely. The topography plays a dominant role in determining the spatial distribution of total precipitation in Catalonia (PRCPTOT index). The greatest values are correlated with the Catalan reliefs, with the maximum values over $1000 \mathrm{~mm}$ per year in the northern sector of the region, i.e. close to the Pyrenees, and a secondary maximum along the smaller mountain ranges located along the coast. The 

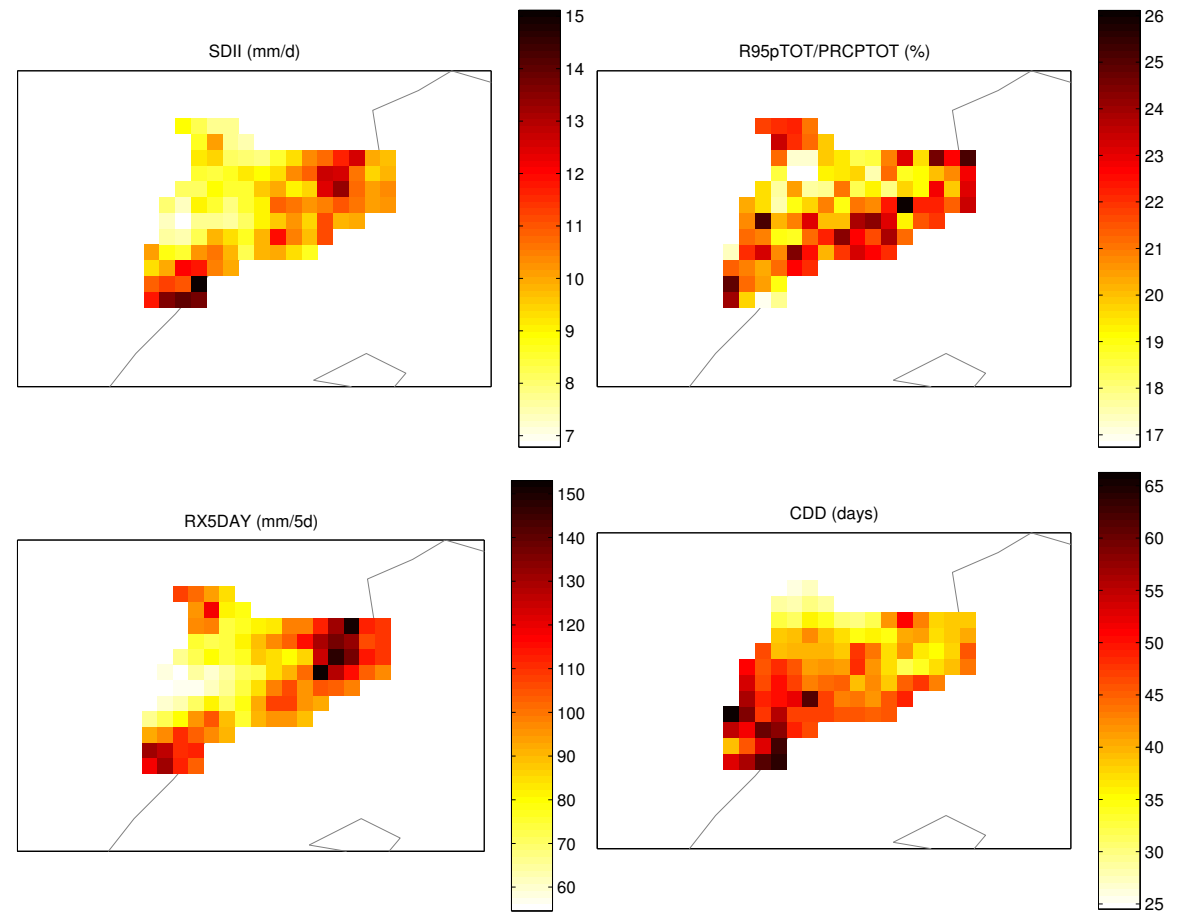

Fig. 4. Spatial distribution of the mean values (averaged over the studied period, 1951-2003) of the precipitation indices shown in Table 1 (except the PRCPTOT index, shown in Fig. 3).

Table 1. Indicators of subset of the ETCCDI precipitation indices used in this study, see also http://cccma.seos.uvic.ca/ETCCDI.

\begin{tabular}{|c|c|c|}
\hline Name & Description & Definition \\
\hline PRCPTOT (mm) & Total precipitation in wet days & $\begin{array}{l}\text { Let } R R_{\mathrm{wj}} \text { be the daily precipitation amount on } \\
\text { a wet day } w(R R \geq 1 \mathrm{~mm}) \text { in period } j . \\
\text { Then PRCPTOT } \text { PR }_{j}=\operatorname{sum}\left(R R_{\mathrm{wj}}\right)\end{array}$ \\
\hline $\operatorname{SDII}\left(\mathrm{mm} \mathrm{d}^{-1}\right)$ & $\begin{array}{l}\text { Mean precipitation amount on a wet day } \\
\text { (Simple Daily Intensity Index) }\end{array}$ & $\begin{array}{l}\text { If } W \text { represents the number of wet days in period } j \text { then } \\
\text { the simple precipitation intensity index } \operatorname{SDIIj}=\text { sum } \\
\left(R R_{\mathrm{wj}}\right) / W \text {. }\end{array}$ \\
\hline $\begin{array}{l}\text { R95p=R95pTOT/ } \\
\text { PRCPTOT }(\%)\end{array}$ & $\begin{array}{l}\text { Percentage of precipitation due to very } \\
\text { wet days (heavy rainfall proportion) }\end{array}$ & $\begin{array}{l}\text { Let RRwn95 be the } 95 \text { th percentile of precipitation on } \\
\text { wet days in the base period } n(1961-1990) \text {. Then } \\
\text { R95pTOTj = sum }\left(R R_{\mathrm{wj}}\right) \text {, where } R R_{\mathrm{wj}}>\text { RRwn95. } \\
\text { The ratio R95pTOT/PRCPTOT represents the } \\
\text { percentage of precipitation due to very wet days. }\end{array}$ \\
\hline 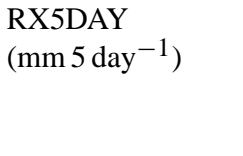 & $\begin{array}{l}\text { Highest precipitation amount in } \\
\text { five-day period }\end{array}$ & $\begin{array}{l}\text { Let } R R_{\mathrm{kj}} \text { be the precipitation amount for the five-day } \\
\text { interval } k \text { in period } j \text {, where } k \text { is defined by the last } \\
\text { day. The maximum five-day values for period } j \text { are } \\
\operatorname{RX}^{\text {DAY }} j=\max \left(R R_{\mathrm{kj}}\right) \text {. }\end{array}$ \\
\hline CDD (days) & $\begin{array}{l}\text { Maximum length of dry spell } \\
\text { (Consecutive Dry Days) }\end{array}$ & $\begin{array}{l}\text { Let } R R_{\mathrm{ij}} \text { be the daily precipitation amount on day } i \text { in } \\
\text { period } j \text {. Count the largest number of consecutive days } \\
\text { where } R R_{\mathrm{ij}}<1 \mathrm{~mm} \text {. }\end{array}$ \\
\hline
\end{tabular}

minimum values are reached in the inner western, with less than $400 \mathrm{~mm}$ per year.

The climatology of the other indices (Fig. 4) is quite different from the PRCPTOT index, in particular for the location of the areas with the maximum values. For the climatology map of the SDII index, the maximum values, amounting to about $15 \mathrm{~mm}_{\text {day }}{ }^{-1}$, are located in the extreme North and South of the coastal area. Note that this spatial distribution is similar to this one obtained for the contribution of convective precipitation to total precipitation (Llasat et al., 2007). The same happens for the index RX5DAY, with maximums

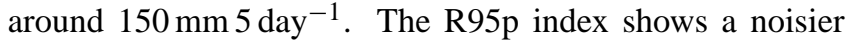


spatial distribution, although it is possible to identify a consistent pattern along the coast, where it achieves the highest percentage of precipitation due to heavy rains (about $25 \%$ ). Finally, the CDD index shows a northwest-south gradient, with minimum values of approximately 25 day in the western Pyrenees and maximum of 65 days in the southern sector of the region.

\subsection{Ensemble-averaged precipitation indices}

The temporal evolution of the indices has been analyzed considering the regional average of the grid-points in the region as representative of all of Catalonia. In order to reduce the possible bias in the regional average, for each grid-point, each index has been calculated at annual and seasonal scale; finally these series have been standardized to unit variance and zero mean and then, the mean over Catalonia has been calculated.

The error produced in the determination of annual (or seasonal) spatial average as a consequence of the variable number of stations available each year to built the dataset (Fig. 5) has been estimated. This sampling error is assessed by means of jack-knife subsampling without replacement (Efron and Tibshirani, 1986; Ciccarelli et al., 2008). Ciccarelli et al. (2008) implemented this method considering a dense observational network of stations in northwestern Italy. They estimated the error in the spatial mean due to the variable number of stations along the time with the following methodology: in each year or season, they computed a spatial average with a random half of the available stations and repeated this operation 1000 times getting a distribution of spatial averages.

In our case, we did not work with stations, but with the SPAIN02 grid points over Catalonia. Here we have estimated the "number of reliable points" (Npoints) with the hypothesis that the number of SPAIN02 points with greater reliability is larger when more stations are available. The practical implementation of this methodology is resumed here. For each year (or season):

1. The Npoints are estimated. This is done considering the number of available station (Nstations) with at least $99 \%$ of valid daily data within each year (Fig. 2) and solving this proportion:

$112: 263=$ Npoints : Nstations,

where 112 are the grid points of the SPAIN02 in Catalonia and 263 is the maximum number of precipitation stations used to build the dataset.

2. From here we have applied the same methodology proposed by Ciccarelli et al. (2008). That is, a random half of the Npoints is selected (i.e. if the number of available stations in the year 1951 was 80 , then we select randomly the half (17) of the Npoints, such as 112 : $263=$ Npoints : 80 ).
Table 2. Comparison (Pearson correlation, $\rho$, and mean error in \%, ME; see the text for the definition) between the two series Fabra and Ebro and the points of SPAIN02 closest to these series (the correlations are significant at $99 \%$ ).

\begin{tabular}{l|cc|cc}
\hline \multirow{2}{*}{ INDEX } & \multicolumn{2}{|c|}{ SPAIN02 vs. FABRA } & \multicolumn{2}{c}{ SPAIN02 vs. EBRO } \\
\cline { 2 - 5 } & $\rho$ & ME & $\rho$ & ME \\
\hline PRCPTOT & 0.81 & -20 & 0.86 & -12 \\
SDII & 0.60 & -5 & 0.66 & -6 \\
R95p & 0.67 & -2 & 0.77 & -16 \\
RX5DAY & 0.78 & -13 & 0.83 & -9 \\
CDD & 0.58 & 24 & 0.65 & 21 \\
\hline
\end{tabular}

3. The spatial average for each specific index for this year (or season) has been computed with this subset.

4. The steps 2 and 3 were repeated many times (1000) in order to have a distribution function of average values for each year (or season). From this distribution, the $99 \%$ confidence bands were estimated.

All the time series of the annual indices show that the sampling error is relatively low compared with the large interannual variability (Fig. 5). This error is greater for the period 1995-2000 approximately, and in agreement with the fact that at this time there was the minimum number of stations used to build the dataset. The seasonal indices indicate the same result (not shown here).

\subsection{Comparison between SPAIN02 and station data}

In this section we have provided evidence of the quality of this dataset by evaluating its representativeness by comparing it with the two reference stations, Fabra and Ebro observatories. The two respective closest points of SPAIN02 are compared with the stations by means of two metrics: the Pearson correlation, $\rho$ (considering only significant correlation at $99 \%$ ), and the mean error (ME) standardized in respect to the mean of the SPAIN02 series:

$\mathrm{ME}=100 \cdot \frac{1}{N \cdot \operatorname{mean}(\mathrm{STN})} \sum_{i=1}^{N}(\mathrm{SP} 02(i)-\operatorname{STN}(i))$

where $N$ is the length of the series (in this case $53 \mathrm{yr}$ ), $\operatorname{STN}(i)$ the Fabra or the Ebro series and SP02(i) is the series of the SPAIN02 point closest to the station.

In general there is a quite good correlation with the series (Table 2), with values above 0.8 for the PRCPTOT index and around 0.7 or more for the R95p and RX5DAY indices. The lower values are obtained for the SDII and CDD indices, with correlations around $0.6-0.65$. This is probably due to their high sensitivity to the count of the number of rainy days. For example, erroneously considering a rainy day in the middle 

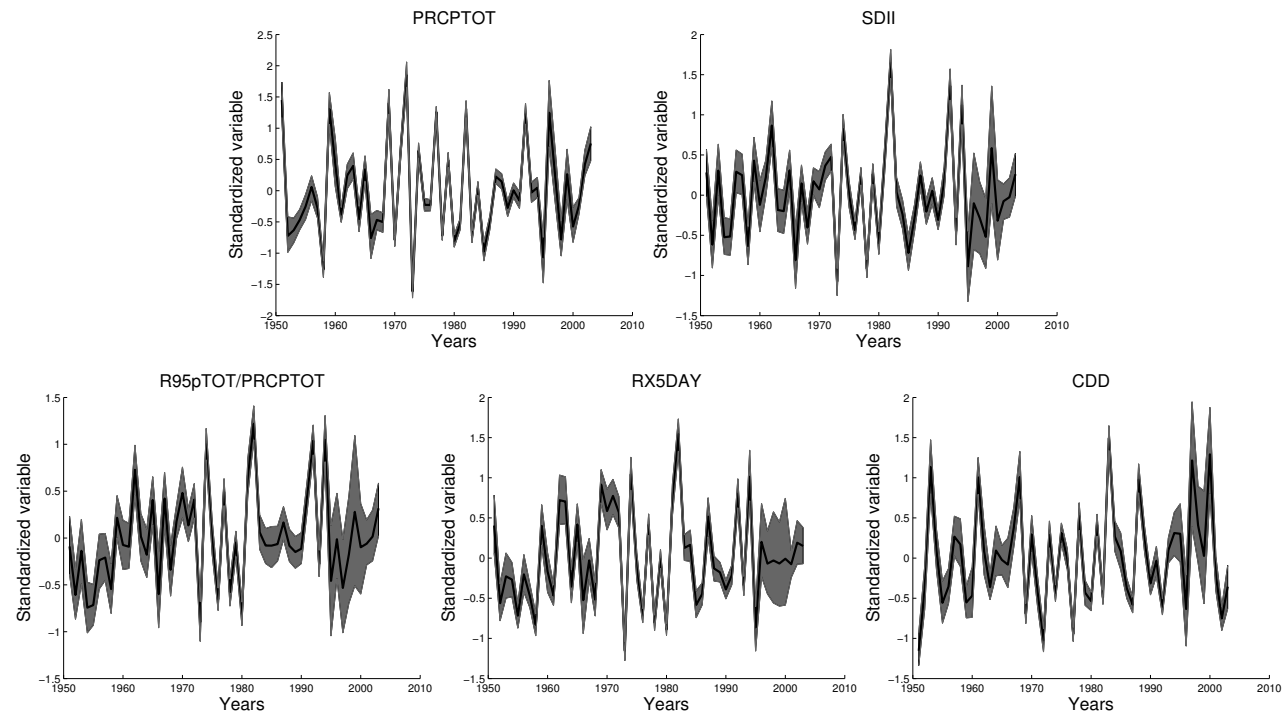

Fig. 5. Annual regional averaged time series for the precipitation indices shown in Table 1. The series are standardized. Gray bands indicate $99 \%$ confidence bands obtained by a jack-knife subsampling technique.
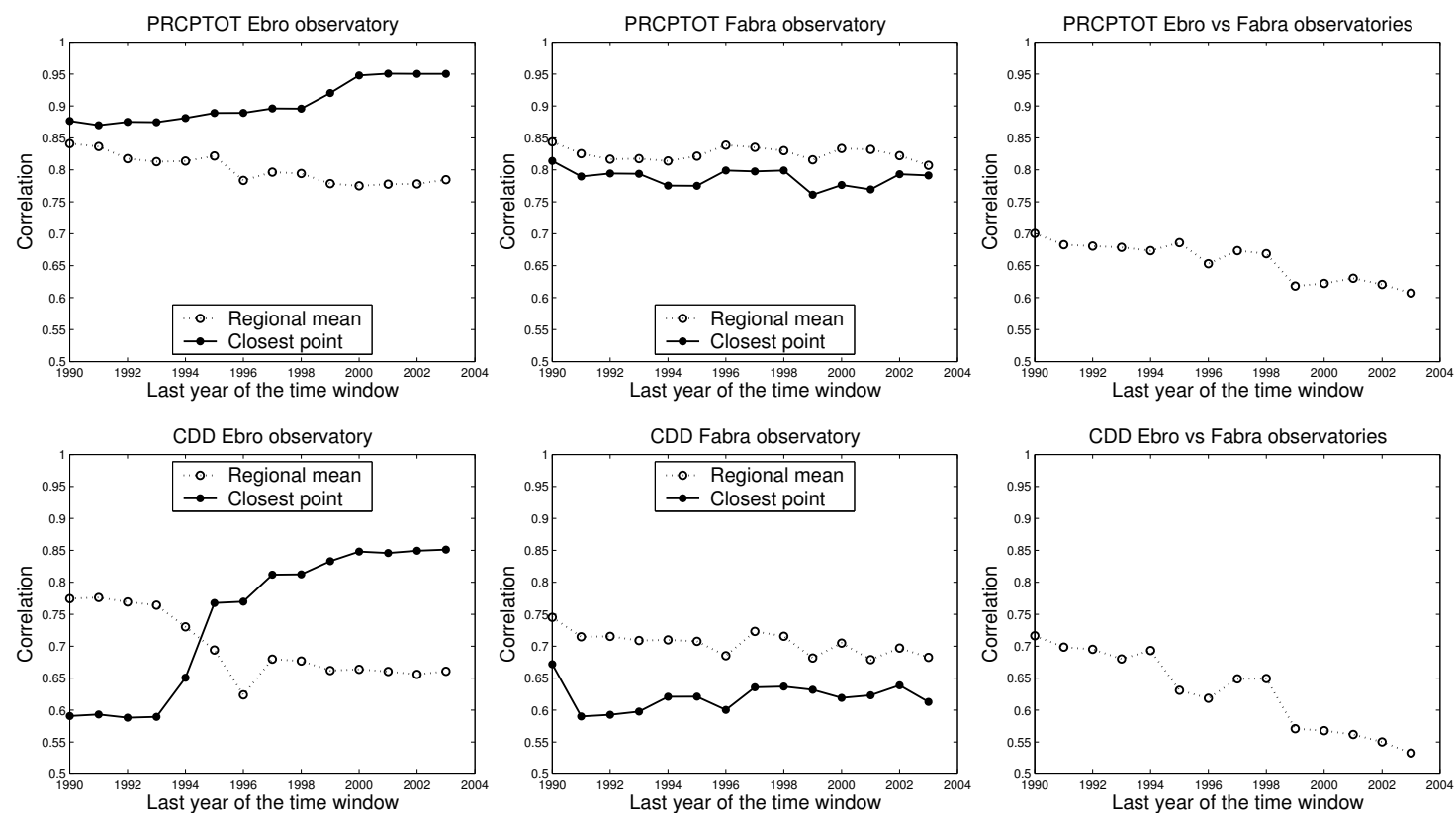

Fig. 6. Correlation for the PRCPTOT (top) and CDD (bottom) indices between the series Ebro and Fabra and the points of SPAIN02 closest to these series and the regional average (first 2 columns) and the correlation between the two observatories (last column). The correlation is applied considering a moving time-window of $40 \mathrm{yr}$. Years along the $\mathrm{x}$-axis indicate the later years of the time window, for example, 1990 indicates the final year of the series that began in 1951.

of a long series of days without rain can cause a large error in calculating the index CDD.

The SPAIN02 point presents an underestimation of the precipitation (Table 2), with greater error (around $20 \%$ ) for the PRCPTOT and the CDD indices. This underestimation is a consequence of the comparison between areal values (SPAIN02 provides average precipitation over an area of
$400 \mathrm{~km}^{2}$ ) and point values in a region with a high spatial variability in precipitation.

In the perspective of the subsequent trend analysis, we have evaluated if the correlation between SPAIN02 and both series changes in time. For this purpose, the correlation evolution between the stations and their closest points and between the stations and the regional average of SPAIN02 is 

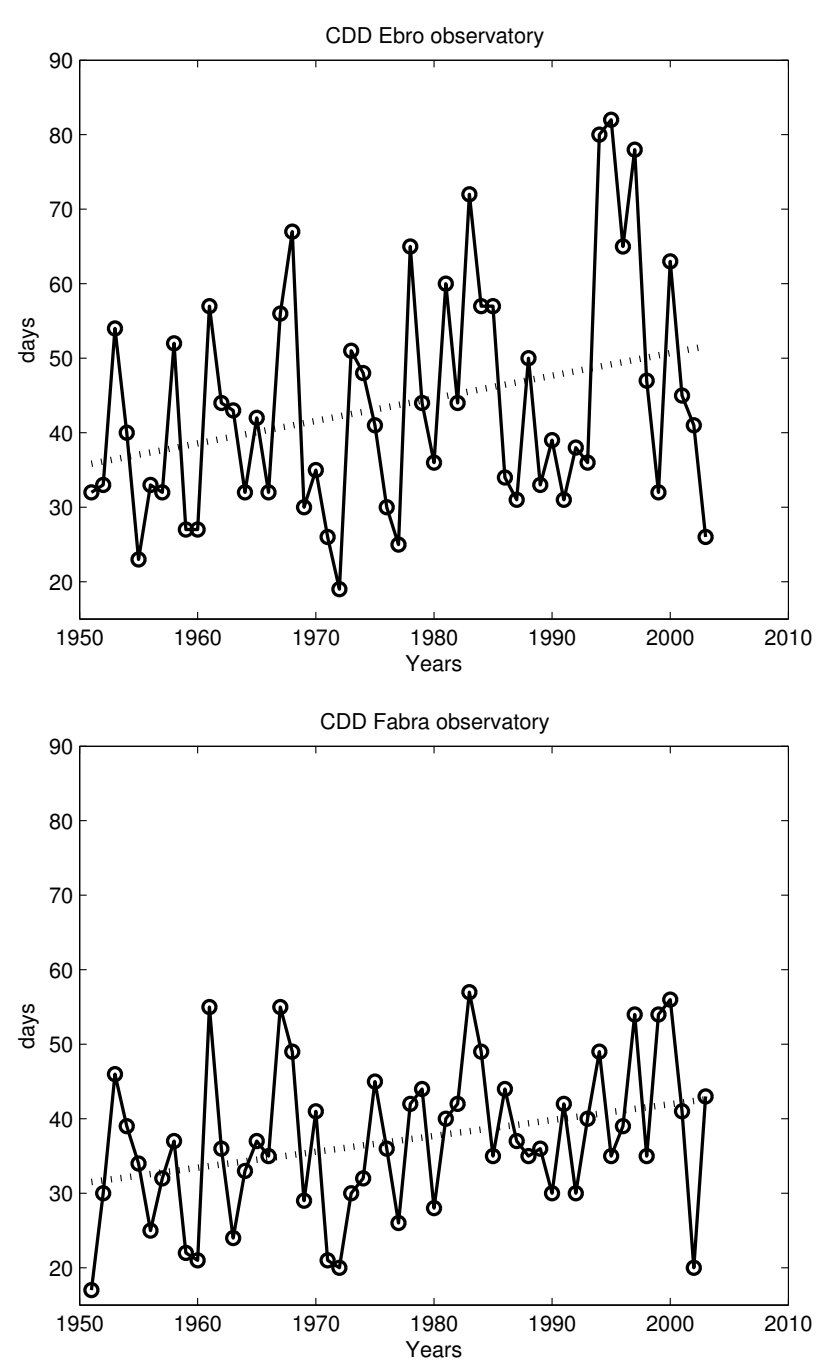

Fig. 7. Time series of the annual CDD index for the Ebro (top) and Fabra (bottom) Observatories. Both stations show a significant trend $(99 \%)$ of 2.7 and 2,1 days decade ${ }^{-1}$, respectively.

calculated. The correlation evolution is obtained applying a moving time-window of $40 \mathrm{yr}$ (i.e. the first correlation is calculated for the period 1951-1990, the second for the period 1952-1991 and so on). In addition, the correlation evolution between both stations is analyzed.

Results are shown in Fig. 6. For the sake of brevity and since in the next section we focus more on these indices, only the indices PRCPTOT and CDD are shown. However, note that these two indices have the best (PRCPTOT) and worst (CDD) correlation considering the whole series, as can be seen in Table 2. Considering the PRCPTOT index, both for the nearest point and for the regional average values, there are high correlations, quite stable over time (mainly for Fabra observatory). For the CDD index, the correlations are slightly lower and, while for Fabra the values are again quite stable over time, this is not the case for the Ebro observa- tory. Note that, also for this index, the correlation between both observatories is decreasing. On the contrary, the correlation between Ebro and its nearest point increase, whereas for the regional average the behavior is the opposite. This decreasing correlation may be the result of the number of available stations influence but, also, it could point to a different climatic evolution of the Ebro observatory in comparison with the rest of Catalonia. This result suggests greater care in the analysis of the CDD index. However, apart from these trends, it is important to note that the variation of the correlation is lower in the case of the regional average (ranging from around 0.75 and 0.65 ), than in the case of the gridpoint (ranging from around 0.60 and 0.85 ). It is also lower than the variation in the correlation between the two stations. This fact, combined with the temporal stability correlations for the other indices and the other station, suggests that the regional average can be considered quite homogeneous and that greater caution is needed considering the individual grid points of the dataset.

Finally, by analyzing in more detail the comparison between both stations, a decrease of the correlation considering the more recent periods seems to indicate that if artificial anomalies are excluded (as in this case it is legitimate to assume), the climate evolution in both stations diverges (note that this fact is more pronounced considering the CDD index). As already noted, the comparison of the three series (Ebro, Fabra and the regional averaged series) suggests that the climate evolution of the Ebro observatory is moving away also from the mean climate in Catalonia. This local behaviour suggests that care must be taken in drawing conclusions at regional scale by analyzing only a few stations.

\section{Trend analysis}

\subsection{Methodology}

Trend analysis is applied to the annual and seasonal values of the five ETCCDI indices for the two high-quality stations, for each grid-point of the SPAIN02 dataset in the region, and the average of them as representative of the whole Catalonia. As already mentioned, we focus on the spatial average since it has fewer inhomogeneities compared to the series at the individual grid-points. Indeed, the pattern trend at individual grid-points has been analyzed with caution, considering only the maps with field significance at least greater than $95 \%$, (Livezey and Chen, 1983; Renard et al., 2008) showing also spatially coherent patterns of trend, i.e. patterns of similar trends affecting neighboring points. Indeed, a similar trend should be detected at many stations in a zone since only trends relating to a large-scale driver of change are worth analyzing. Instead, noisy trend patterns most probably imply stochastic noise.

In order to analyze the influence of the length series, 24 series have been constructed. The first series starting in 1951 
(a) $1951-2003$

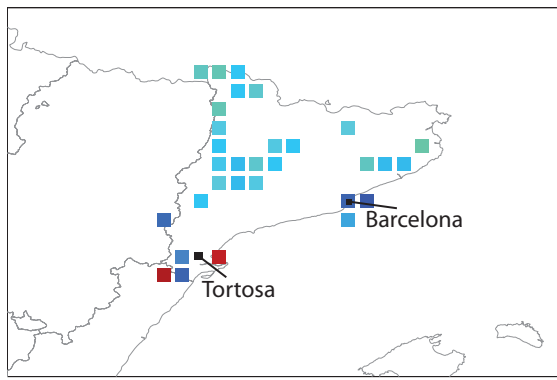

(c) $1963-2003$

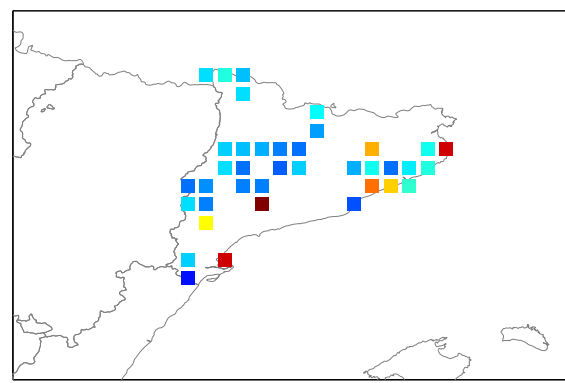

(b) $1957-2003$

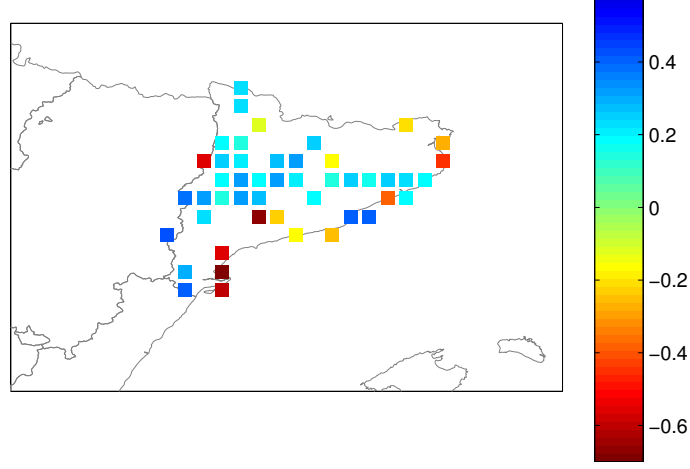

(d) $1969-2003$

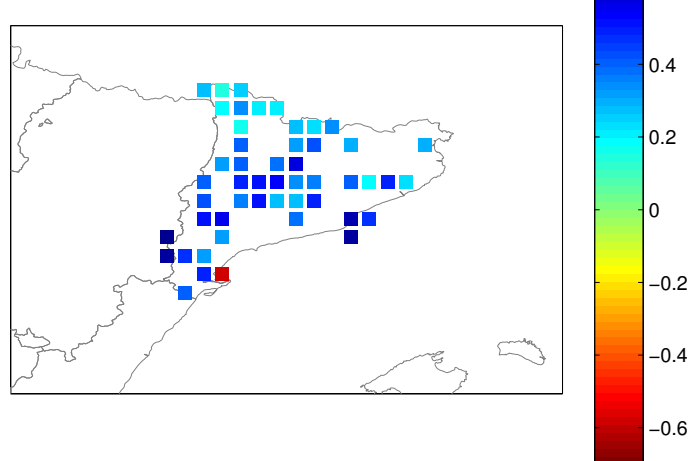

Fig. 8. Maps of the trend for the annual CDD index considering different time windows as reported on the top of each figure. The units are day $\mathrm{yr}^{-1}$. These trend patterns have a field significance of $99 \%$.

and ending in 2003, the second starting in 1952 and ending in 2003, and so on; the last one is the series starting in 1974 and ending in 2003, in order to consider the minimum climate interval of $30 \mathrm{yr}$. Besides this, 14 other series have been built to analyze the potential influence of the departure point and of the analyzed period. These series are obtained considering a moving time-window of $40 \mathrm{yr}$, moving in advance year by year (i.e. analyzing the times series ranging from 1951 to 1990, from 1952 to 1991, and so on). Other running windows approaches can be found in some trend studies (e.g. Brunetti et al., 2006; Zolina et al., 2008; Lupikasza, 2010).

Since the extreme precipitation indices generally have non-Gaussian distributions and could be not independent (WMO, 2009), the standard methods to estimate the significance of the trends could be unreliable (Alexander et al., 2006). For example, when the null hypothesis in the MannKendall test is not satisfied (i.e. when the data are not independent and not randomly ordered), there is more probability of detecting trends when actually none exist and vice-versa (Hamed and Ramachandrarao, 1998). In Moberg and Jones (2005) there is a short review of different methods that takes into account these problems (i.e. non-normal distribution and autocorrelation) concluding that there is no universally preferred method.

Among these methods, the "moving block bootstrap" method developed by Kiktev et al. (2003) was chosen here because it provides a rigorous and simply interpretable methodology for analyzing trends in extreme precipitation indices. This method consents to analyze non-Gaussian distribution, and to deal with the temporal correlation in the residuals of the linear regression (resampling block of consecutive years), and to preserve the spatial dependence structure of observations (using the same resampling sequence for each individual point and within each iteration of the bootstrap). This method also provides the field significance of the spatial observed trends considering therefore the interdependence between the stations (or grid-points) (Livezey and Chen, 1983; Renard et al., 2008).

For more details on the original implementation of this method, the readers are referred to Kiktev et al. (2003). Our practical implementation is slightly different and it is summarized here. Note that our code to implement this method 


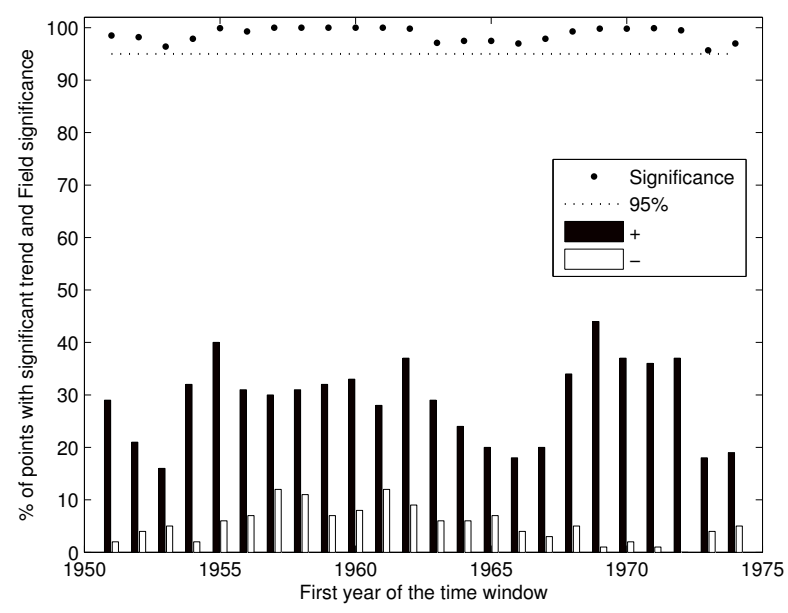

Fig. 9. Percentage of points with significant trend, negative $(-$, white bar) and positive (+, black bar) of the annual CDD index with the corresponding field significance (point) in function of the length of the trend period considered since all the series finish in 2003 (e.g. the "First year of the time window" of 1951 years means the period starting in 1951 and ending in 2003, while 1974 means it lasts $30 \mathrm{yr}$, since it finished in the year 2003).

is publicly available on this website: http://www.am.ub.es/ $\sim$ mturco/codes/testTrend_MT.zip. For each grid point (or station):

1. Subtract linear trend from the original series obtaining the time series of residuals (or noise).

2. Resample time series of residuals 1000 times, obtaining new plausible time series of noise. Our modifications regard this resampling:

a. Instead of the "moving block bootstrap" used in Kiktev et al. (2003), here the circular block bootstrap (Politis and Romano, 1992; Zoubir and Boashash, 1998) was used in order to avoid the problem of the values in the middle of a series having a greater chance of being included in the resample in the "moving block bootstrap";

b. In order to choose the block length (BL) for the circular block bootstrap, the method described in Politis and White (2004) was used. This method has the advantage of being a non-parametric technique (Politis and White, 2004).

3. Add the original linear trend onto 1000 resampled time series of noise and re-estimate the trend obtaining 1000 new plausible trend values.

4. Calculate the significance of the trend considering if the zero-trend falls outside the distribution of these 1000 plausible trend values.
5. When applied to more stations (or grid-points) in a region, the field significance is calculated comparing the percentage area of significant grid points due to natural variability alone (calculated by taking the difference between each of the 1000 patterns of the pseudo-trends and the actual trend) and the percentage area of significant grid points in the actual trend pattern.

To estimate the block of consecutive years to resample (BL), Kiktev et al. (2003) and Moberg and Jones (2005) used the methodology presented in Wilks (1997); this method assumes that the time series can be modelled as either a firstor a second-order autoregressive process. They found values among, respectively 2 and 3 , and 2 and 4 . In our case, the BL was estimated according to Politis and White (2004) and quite similar values were found (see Table 3). The values of the $\mathrm{BL}$ range from 1 to 7 , considering all the 38 different time series. When they are greater than 1 , the residuals are not independent and spurious results could arise using the standard methods (e.g. Mann-Kendall test) to estimate the significance of the linear trends (Hamed and Ramachandrarao, 1998).

The sensitivity of the results to the choice of the BL are provided in the next section.

\subsection{Trend analysis results}

Already by visual inspection of Fig. 5, we observe that the annual series of indices show no major trend, but rather a large interannual variability. The statistical analysis confirms this result: no trends are found for the annual series of all the indices and considering all the different time windows. The trend analysis of the Ebro and Fabra stations agrees with this result with one exception: both series show a significant increase in the maximum length of dry spell (CDD index, Fig. 7). In details, the Ebro observatory has an increase of 2.7 days decade ${ }^{-1}$, while the trend is 2.1 days decade $^{-1}$ for the Fabra observatory. Both trends are significant at $99 \%$. Note that the block length for the Ebro series is equal to 2; thus, the autocorrelation of the series of residuals (see previous section) is not negligible. In this case the standard MannKendall test could be unreliable since its null hypothesis is not satisfied (i.e. the data are not independent and not randomly ordered). Note that this test gives a p-value equal to 0.07 , which is higher than the standard limit of 0.05 . In this case, by applying the Mann-Kendall test improperly, a significant trend could be neglected. Instead, for the Fabra series the block length is equal to 1 . In this case, the Mann-Kendall test confirms the significance of the trend ( $p$-value $=0.02$ ), as expected.

To analyze this trend in greater depth and take the limitations discussed above into account, the trends of the SPAIN02 dataset at grid-point scale have been explored with caution. A coherent and field significant trend pattern has been found regarding the annual CDD index, with around $30 \%$ of the grid-points showing an increase of around 2 days decade ${ }^{-1}$. The majority of the significant grid-points 

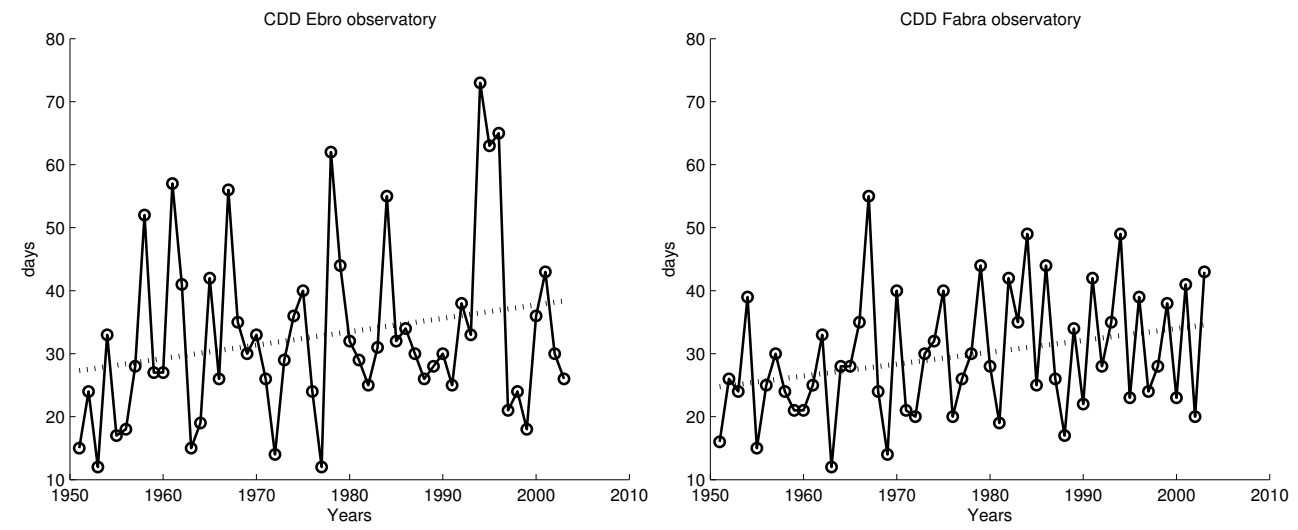

Fig. 10. Time series of the summer CDD index for the Ebro (left) and Fabra (right) Observatories. Both stations show a significant trend (99\%) of, respectively, 2.7 and 2,1 days decade ${ }^{-1}$.
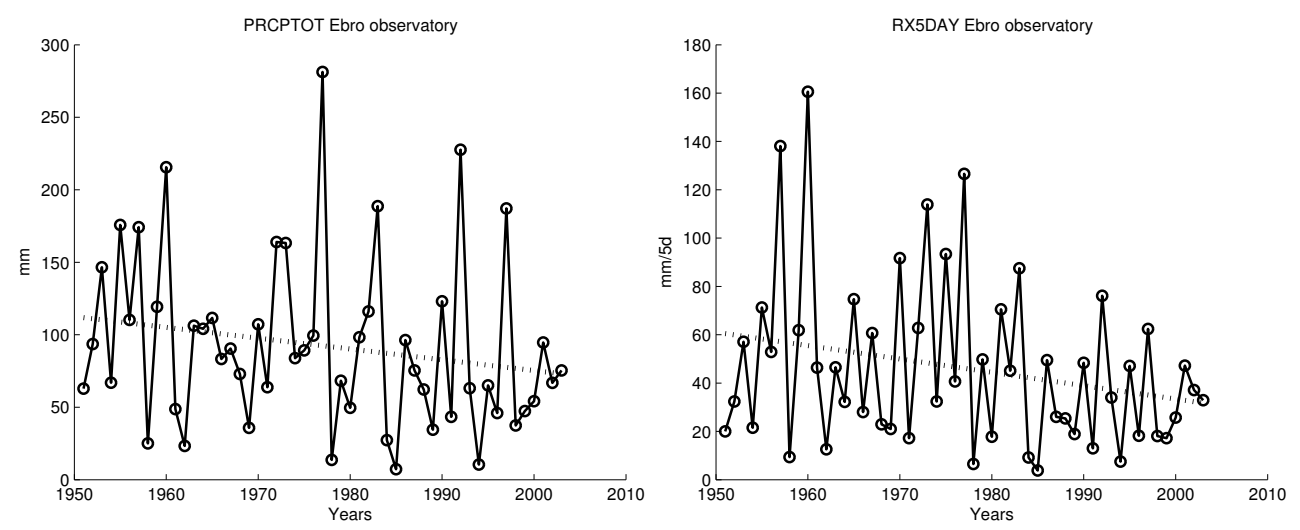

Fig. 11. Time series of the summer PRCPTOT (left) and RX5DAY (right) indices for the Ebro observatory.

Table 3. Range (considering the 38 different time series) in block lengths (BL, in years) used in the circular block bootstrap estimate according to Politis and White (2004), for the different periods and indices studied.

\begin{tabular}{lccccc}
\hline Index & Year & DJF & MAM & JJA & SON \\
\hline PRCPTOT & $5-7$ & $1-6$ & $1-6$ & $1-2$ & $1-2$ \\
SDII & $3-7$ & $2-6$ & $1-2$ & 1 & $1-6$ \\
R95p & $2-5$ & $1-4$ & $1-2$ & 1 & $1-2$ \\
RX5DAY & $2-5$ & $3-6$ & $1-6$ & 1 & $1-2$ \\
CDD & $2-7$ & $1-7$ & $1-2$ & $1-2$ & $1-6$ \\
\hline
\end{tabular}

are in the inner part of Catalonia and close to the position of the two stations analyzed here (Fig. 8). This general feature does not change greatly, moving the length of the time series with a percentage of grid-points with a positive trend ranging between approximately 20 and $30 \%$, depending on the time-window used (Fig. 9). Also considering a time window of $40 \mathrm{yr}$ moving in advance, year by year, confirms this local increase in the annual longest dry period index (not shown).

The trends found at annual scale suggest exploring what season contributes more to these trends. Note, however, that the longest period without rainfall can occur across two seasons, so an increase (decrease) in annual CDD index may not correspond to an increase (decrease) of this index at seasonal scale. Nevertheless, both stations show a significant $(99 \%)$ increase in the number of consecutive days dry in summer (around 2 days decade $^{-1}$, Fig. 10), the season with less precipitation in Catalonia, as typical of Mediterranean areas (Romero et al., 1998). These trends do not seem to be representative for all of Catalonia: the regional average of SPAIN02 does not show any trend.

No other common seasonal trends has been found. Only in summer, for the Ebro observatory, two indices show a significant (greater than 95\%) trend. Both the PRCPTOT and RX5DAY index show a significant negative trend, amounting respectively to around $-10 \mathrm{~mm} \mathrm{decade}^{-1}$ and $-5 \mathrm{~mm} \mathrm{decade}^{-1}$ (Fig. 11). 


\section{Conclusions}

The goal of this study has been to analyze the extreme rainfall variability in Catalonia (northeastern Iberian Peninsula) during the second half of the 20th century (1951-2003) in order to better understand the climatic variability of precipitation extremes and to set up the basis for the development of regional climate scenarios within the framework of the Spanish project esTcena. This objective has been achieved by performing a statistical assessment that is both robust, e.g. extensively using Monte-Carlo methods like bootstrap and jack-knife, and comparable, e.g. considering a subset of the extreme precipitation indices defined by the Expert Team on Climate Change Detection and Indices (ETCCDI indices). These indices have been calculated from a new, recently developed, interpolated dataset of daily precipitation, namely SPAIN02, regular at $0.2^{\circ}$ horizontal resolution (around $20 \mathrm{~km}$ ), and from two high-quality stations: the Ebro and Fabra observatories. Note that these two stations are the only stations available at daily scale without missing values in Catalonia for the whole studied period.

By using a jack-knife technique, we have found that the error of the spatially averaged series, due to the variable number of stations in time used to build the dataset, is relatively low; besides, the good correspondence with the two highquality stations (Ebro and Fabra observatories) increases the confidence in using SPAIN02 for climate studies. Note, however that the SPAIN02 points closest to the Ebro and Fabra observatories present an underestimation of the precipitation equal to $10-20 \%$. This underestimation is a consequence of the comparison between areal values and point values in a region characterized by high spatial variability in precipitation. Besides this, at the scale of individual pixels the inhomogeneities may be important and imply that analysis is carried out at regional scale. Furthermore, from this comparison, it is apparent that the Ebro station has different behavior than the Fabra station and the regional average of SPAIN02. This suggests that care must be taken in drawing conclusions at regional scale by analyzing only a few stations.

From a methodological point of view, the most important result of this study is the implementation of a circular block bootstrap procedure for the estimation of the significance of the trends (the code to implement this method is publicly available from this website: http://www.am.ub.es/ mturco/ codes/testTrend_MT.zip). This method, besides being easy to interpret, deals with autocorrelated series for which the hypothesis of the classical test such as Mann-Kendall fails, as happened with the series analyzed here. Indeed, we have provided evidence that when the data are not independent, the classical Mann-Kendall test incorrectly neglects some significant trends. In this study a modified version of the procedure proposed by Kiktev et al. (2003) has been implemented; instead of using a moving block bootstrap as done originally, the circular block bootstrap (Politis and Romano, 1992) has been used here. This modification has been done in order to avoid the problem of the values in the middle of a series having a greater chance of being included in the resample in the "moving block bootstrap".

Trend analysis has been applied to the annual and seasonal series of a subset of the ETCCDI indices for the SPAIN02 and for both stations. In order to analyze the influence of the interdecadal variability, a running trend analysis (i.e. considering different period lengths) has been performed. One of the most important outcomes of this work is that only the consecutive dry days (CDD) index at annual scale shows a spatial coherent pattern of trend. Both stations and around $30 \%$ of the area of Catalonia show an increase of around $2-3$ days decade ${ }^{-1}$. Instead, considering the standardized regional average of the grid points of SPAIN02, no trends have been observed at annual or at seasonal scale.

Even if no other consistent regional trend pattern was found, some local trends are worth mentioning. There is a common increase in the CDD index for both station of around 2 days decade $^{-1}$ in summer. There is also a significant decrease in total precipitation (around $-10 \mathrm{~mm} \mathrm{decade}^{-1}$ ) and in the index "highest precipitation amount in five-day period" (RX5DAY, around $\left.-5 \mathrm{~mm} \mathrm{decade}^{-1}\right)$ in summer for the Ebro observatory.

It is likely that considering more recent years, which will be the subject of our future research, this local trend in CDD index persists or increases. Indeed, a recent study (AltavaOrtiz, 2010) indicates that the severity (intensity and duration) of the drought in 2004-2008 was higher than any other event of the twentieth century. With this aim, the present study will be applied to the updated version until 2010 of the Spain02 dataset, once this is available.

Acknowledgements. This work was supported by esTcena project (Exp. 200800050084078), a strategic action from Plan Nacional de I+D+i 2008-2011 funded by Spanish Ministry of Medio Ambiente y Medio Rural y Marino. The authors thank AEMET and the University of Cantabria for the data provided for this work (Spain02 gridded precipitation data set) and thank Ebro and Fabra Observatories for the station data.

Edited by: R. Crockett

Reviewed by: M. Lang and another anonymous referee

\section{References}

Alexander, L. V., Zhang, X., Peterson, T. C., Caesar, J., Gleason, B., Klein Tank, a. M. G., Haylock, M., Collins, D., Trewin, B., Rahimzadeh, F., Tagipour, a., Rupa Kumar, K., Revadekar, J., Griffiths, G., Vincent, L., Stephenson, D. B., Burn, J., Aguilar, E., Brunet, M., Taylor, M., New, M., Zhai, P., Rusticucci, M., and Vazquez-Aguirre, J. L.: Global observed changes in daily climate extremes of temperature and precipitation, J. Geophys. Res., 111, D05109, 2006.

Alexander, L. V., Tapper, N., Zhang, X., Fowler, H. J., Tebaldi, C., and Lynch, A.: Editorial Climate extremes: progress and future directions, International J. Climatol., 29, 317-319, 2009. 
Alpert, P., Ben-Gai, T., Bahrahad, A., Benjamini, Y., Yekutieli, D., Colacino, M., Diodato, L., Ramis, C., Homar, V., Romero, R., and Others: The paradoxical increase of Mediterranean extreme daily rainfall in spite of decrease in total values, Geophys. Res. Lett., 29, 31-1, 2002.

Altava-Ortiz, V.: Caracteritzacío i monitoratge de les sequeres a Catalunya i nord del País Valencìa. C'alcul descenaris climàtics per al segle XXI (Characterising and monitoring droughts in Catalonia and Northern Valencian Country. Calculation of climatic scenarios for the 21st century, Ph.D. thesis, University of Barcelona, 2010.

Altava-Ortiz, V., Llasat, M. C., Ferrari, E., Atencia, A., and Sirangelo, B.: Monthly rainfall changes in Central and Western Mediterranean basins, at the end of the 20th and beginning of the 21st centuries, Int. J. Climatol., 31(13), 1943-1958, 2011.

Barrera, A., Llasat, M. C., and Barriendos, M.: Barrera, A., Llasat, M. C., and Barriendos, M.: Estimation of extreme flash flood evolution in Barcelona County from 1351 to 2005, Nat. Hazards Earth Syst. Sci., 6, 505-518, doi:10.5194/nhess-6-505-2006, 2006.

Brunetti, M., Maugeri, M., Nanni, T., Auer, I., Böhm, R., and Schöner, W.: Precipitation variability and changes in the greater Alpine region over the 1800-2003 period, J. Geophys. Res., 111, D11107, 2006.

Ciccarelli, N., Von-Hardenberg, J., Provenzale, A., Ronchi, C., Vargiu, A., and Pelosini, R.: Climate variability in north-western Italy during the second half of the 20th century, Global Planet. Change, 63, 185-195, 2008.

Cunillera, J.: Escenaris Climàtics: Indicadors climàtics per al seguiment, in: Aigua i canvi climàtic. Diagnosi dels impactes previstos a Catalunya, 53-62, Agència Catalana de l'Aigua, 2009.

Efron, B. and Tibshirani, R.: Bootstrap Methods for Standard Errors, Confidence Intervals, and Other Measures of Statistical Accuracy, Statistical Science, 1, 54-75, 1986.

García, J. A., Gallego, M. C., Serrano, A., and Vaquero, J. M.: Trends in Block-Seasonal Extreme Rainfall over the Iberian Peninsula in the Second Half of the Twentieth Century, J. Climate, 20, 113-130, 2007.

Giorgi, F.: Climate change hot-spots, Geophys. Res. Lett., 33, L08707, doi:10.1029/2006GL025734, 2006.

Giorgi, F. and Lionello, P.: Climate change projections for the Mediterranean region, Global Planet. Change, 63, 90-104, 2008.

Gonzalez-Hidalgo, J. C., Martin-Vide, J., and Luis, M. D.: Monthly precipitation trends on the Mediterranean fringe of the Iberian Peninsula during the second-half of the twentieth century (19512000), Int. J. Climatol., 29, 1415-1429, 2009.

Goodess, C. M. and Jones, P. D.: Links between circulation and changes in the characteristics of Iberian rainfall, Int. J. Climatol., 22, 1593-1615, 2002.

Hamed, K. and Ramachandrarao, A.: A modified Mann-Kendall trend test for autocorrelated data, J. Hydrol., 204, 182-196, 1998.

Herrera, S., Gutierrez, J. M., Ancell, R., Pons, M. R., and Frías, M. D., and Fernández, J.: Development and analysis of a 50-year high-resolution daily gridded precipitation dataset over Spain (Spain02), Int. J. Climatol., doi:10.1002/joc.2256, 2010a.

Herrera, S., Fita, L., Fernández, J., and Gutiérrez, J. M.: Evaluation of the mean and extreme precipitation regimes from the $\mathrm{EN}$ SEMBLES regional climate multimodel simulations over Spain, J. Geophys. Res., 115, D21117, doi:10.1029/2010JD013936,
$2010 b$.

Hofstra, N., New, M., and McSweeney, C.: The influence of interpolation and station network density on the distributions and trends of climate variables in gridded daily data, Clim. Dynam., 35, 841-858, 2010.

Kiktev, D., Sexton, D. M. H., Alexander, L., and Folland, C. K.: Comparison of Modeled and Observed Trends in Indices of Daily Climate Extremes, J. Climate, 16, 3560-3571, 2003.

Kristensen, P.: Water Resources: Quantity and Flows, Publications Office of the European Union, http://www.eea.europa.eu/soer/ europe/water-resources-quantity-and-flows, 2010.

Livezey, R. E. and Chen, W. Y.: Statistical Field Significance and its Determination by Monte Carlo Techniques, Mon. Weather Rev., 111, 46-59, 1983.

Llasat, M. C.: High magnitude storms and floods, in: The Physical Geography of the Mediterranean, edited by: Woodward, J., Oxford University Press, 513-540, 2009.

Llasat, M. C. and Quintas, L.: Stationarity of Monthly Rainfall Series, Since the Middle of the XIXth Century, Application to the Case of Peninsular Spain, Nat. Hazards, 31, 613-622, 2004.

Llasat, M. C., Barriendos, M., Barrera, A., and Rigo, T.: Floods in Catalonia (NE Spain) since the 14th century, Climatological and meteorological aspects from historical documentary sources and old instrumental records, J. Hydrol., 313, 32-47, 2005.

Llasat, M.-C., Ceperuelo, M., and Rigo, T.: Rainfall regionalization on the basis of the precipitation convective features using a raingauge network and weather radar observations, Atmos. Res., 83, 415-426, 2007.

López-Moreno, J. I., Vicente-Serrano, S. M., Angulo-Martínez, M., Beguería, S., and Kenawy, A.: Trends in daily precipitation on the northeastern Iberian Peninsula, 1955-2006, Int. J. Climatol., 30, 1026-1041, 2010.

Lupikasza, E.: Spatial and temporal variability of extreme precipitation in Poland in the period 1951-2006, Int. J. Climatol., 30 (7), 991-1007, 2010.

Moberg, A. and Jones, P. D.: Trends in indices for extremes in daily temperature and precipitation in central and western $\mathrm{Eu}-$ rope, 1901-99, Int. J. Climatol., 25, 1149-1171, 2005.

Ninyerola, M., Pons, X., Roure, J. M., Martín Vide, J., Raso, J. M., and P, C.: Atles Climàtics de Catalunya, Servei Meteorològic de Catalunya y Departament de Medi Ambient de la Generalitat de Catalunya, 2003.

Norrant, C. and Douguedroit, A.: Monthly and daily precipitation trends in the Mediterranean (1950-2000), Theor. Appl. Climatol., 83, 89-106, 2005.

Politis, D. N. and Romano, J. P.: A circular block-resampling procedure for stationary data, in: Exploring the Limits of Bootstrap, edited by: LePage, R. and Billard, L., 236-270, John Wiley, New York, 1992.

Politis, D. N. and White, H.: Automatic Block-Length Selection for the Dependent Bootstrap, Econometric Rev., 23, 53-70, 2004.

Pryor, S. C., Howe, J. A., and Kunkel, K. E.: How spatially coherent and statistically robust are temporal changes in extreme precipitation in the contiguous USA?, Int. J. Climatol., 45, 31-45, 2009.

Pujol, N., Neppel, L., and Sabatier, R.: Regional tests for trend detection in maximum precipitation series in the French Mediterranean region / Tests regionaux de detection de tendances dans des series de maxima pluviometriques sur le pourtour Mediterraneen Francais, Hydrolog. Sci. J., 52, 956-973, 2007. 
Renard, B., Lang, M., Bois, P., Dupeyrat, A., Mestre, O., Niel, H., Sauquet, E., Prudhomme, C., Parey, S., Paquet, E., Neppel, L., and Gailhard, J.: Regional methods for trend detection: Assessing field significance and regional consistency, Water Resour. Res., 44, 1-17, 2008.

Río, S., Herrero, L., Fraile, R., and Penas, A.: Spatial distribution of recent rainfall trends in Spain (1961-2006), Int. J. Climatol., 2010.

Rodrigo, F. S.: Changes in the probability of extreme daily precipitation observed from 1951 to 2002 in the Iberian Peninsula, Int. J. Climatol., 30(10), 1512-1525, 2010.

Rodrigo, F. S. and Trigo, R. M.: Trends in daily rainfall in the Iberian Peninsula from 1951 to 2002, Int. J. Climatol., 27, 513529, 2007.

Romero, R., Guijarro, J., Ramis, C., and Alonso, S.: A 30-year (1964-1993) daily rainfall data base for the Spanish Mediterranean regions: First exploratory study, Int. J. Climatol., 18, 541-560, 1998.

Serra, C., Burgueño, A., Martinez, M. D., and Lana, X.: Trends in dry spells across Catalonia (NE Spain) during the second half of the 20th century, Theor. Appl. Climatol., 85, 165-183, 2006.
Turco, M., Quintana-Seguí, P., Llasat, M. C., Herrera, S., and Gutiérrez, J. M.: Testing MOS precipitation downscaling for ENSEMBLES regional climate models over Spain, J. Geophys. Res., 116, D18109, doi:10.1029/2011JD016166, 2011.

Wijngaard, J., Klein Tank, A., and Können, G.: Homogeneity of 20th century European daily temperature and precipitation series, Int. J. Climatol., 23, 679-692, 2003.

Wilks, D. S.: Resampling Hypothesis Tests for Autocorrelated Fields, J. Climate, 10, 65-82, 1997.

WMO: Guidelines on Analysis of extremes in a changing climate in support of informed decisions for adaptation, Tech. Rep. WCDMP No. 72 WMO/TD-No. 1500, WMO, 2009.

Zolina, O., Simmer, C., Kapala, A., Bachner, S., Gulev, S., and Maechel, H.: Seasonally dependent changes of precipitation extremes over Germany since 1950 from a very dense observational network, J. Geophys. Res., 113, 1-17, 2008.

Zoubir, A. M. and Boashash, B.: The bootstrap and its application in signal processing, IEEE Signal Processing Magazine, 15, 1, 56-76, 1998. 